\title{
Degradation of Aqueous Methyl tert-Butyl Ether by Photochemical, Biological, and Their Combined Processes
}

\author{
Azadeh Asadi and Mehrab Mehrvar \\ Department of Chemical Engineering, Ryerson University, 350 Victoria Street, Toronto, ON, Canada M5B 2K3
}

Received 21 February 2006; Revised 9 June 2006; Accepted 10 June 2006

The degradation of aqueous methyl tert-butyl ether (MTBE) at relatively high concentrations was investigated by various photoinduced oxidation processes such as $\mathrm{UV} / \mathrm{H}_{2} \mathrm{O}_{2}$ and $\mathrm{UV} / \mathrm{TiO}_{2}$ as well as biological processes and their combination. It was shown that the degradation of MTBE by $\mathrm{UV} / \mathrm{H}_{2} \mathrm{O}_{2}$ and $\mathrm{TiO}_{2}$ photocatalytic followed a first-order model with apparent rate constant of $1.31 \times 10^{-1}$ and $1.21 \times 10^{-2} \mathrm{~min}^{-1}$, respectively. It was observed that $\mathrm{UV} / \mathrm{H}_{2} \mathrm{O}_{2} / \mathrm{TiO}_{2}$ process did not have any advantages over each of the other processes alone. The biodegradation of methyl tert-butyl ether (MTBE) was evaluated using aerobic mixed culture with three different approaches, including ultimate biological oxygen demand $\left(\mathrm{BOD}_{U}\right)$ assessment, nonacclimated, and acclimated mixed cultures. The apparent rate constant for the biodegradation of MTBE by nonacclimated mixed culture was $4.36 \times 10^{-2}$ day ${ }^{-1}$. It was shown that the acclimatization of the mixed cultures enhanced the rate of biodegradation of MTBE to $3.24 \times 10^{-1} \mathrm{mg} \mathrm{L}^{-1} \mathrm{~h}^{-1}$. Finally, the effects of the photocatalytic pretreatment of aqueous MTBE on its subsequent biological treatment were studied. It was observed that the rate of bioreaction was not enhanced and the photocatalytic pretreatment had adverse effects on its biological treatment so that the apparent rate constant decreased to $2.83 \times 10^{-1} \mathrm{mg} \mathrm{L}^{-1} \mathrm{~h}^{-1}$.

Copyright (c) 2006 A. Asadi and M. Mehrvar . This is an open access article distributed under the Creative Commons Attribution License, which permits unrestricted use, distribution, and reproduction in any medium, provided the original work is properly cited.

\section{INTRODUCTION}

Methyl tert-butyl ether (MTBE) is a chemical compound, which has replaced the lead to enhance the octane number in gasoline. For its oxygen content, MTBE can be added to gasoline up to $15 \%(\mathrm{v})$ to reduce the emission of CO in intercombustion engines [1]. In 1980's, the production of MTBE was increased in the USA and it was in the list of top 50 chemicals produced [2]. MTBE production in the USA was over 200,000 barrels/day in 1999 [3]. MTBE enters the groundwater and soil by leaking aboveground and underground storage fuel tanks, pipelines, refuelling spills, automobile accidents damaging the fuel tank, disposal of old gasoline, marine engines, storm water runoff, and precipitation mixed with MTBE in the air. Its high solubility $(4.8 \%$ at standard pressure and temperature) causes MTBE to transfer to water more than other gasoline compounds [3]. Some events have increased concerns about the health effects of MTBE. In 1992, EPA considered draft health advisory for MTBE equal to $20-200 \mu \mathrm{g} / \mathrm{L}$ in drinking water, which was changed to 20 $40 \mu \mathrm{g} / \mathrm{L}$ in 1997 . In 1999 , the amount of $13 \mu \mathrm{g} / \mathrm{L}$ as health advisory action level was confirmed by the State of California
[2]. Although MTBE is less toxic than other components of gasoline, its low amount in water produces odor and taste problems. Some studies on animal exposure have also shown that MTBE is carcinogenic [4].

Ethers are compounds that are known to be resistant to biodegradation based on the presence of their ether bond [5]. The presence of $t$-butyl group in its molecular structure makes MTBE more defiant to natural biodegradation than other components of gasoline. Two biorecalcitrant functional groups in MTBE structure, ether link and branched, make MTBE resistant to biodegradation [6]. Since bioremediation is usually applied for decomposition of petroleum hydrocarbons, using a method that can be accompanied with biotreatment is appropriate [7]. The complexity and the development of industries in recent years have resulted in new pollutants in wastewater, which cannot be degraded easily by only biological treatment methods. These are effluents from different industries that are mostly toxic and nonbiodegradable. If they are resistant to biodegradation or the high reaction rate is a matter of importance, advanced oxidation processes (AOPs) are used to treat such compounds. AOPs are suitable substitute for phase transfer methods for 
the removal of contaminants from wastewater, but compared to physical and biological treatments, these methods are expensive. Over the past two decades, the interest of exploitation of photooxidation processes for water and wastewater treatment has grown rapidly and chemical oxidation of dissolved pollutants is significantly being considered. High rate of pollution removal and large range of applicability are two major advantages of these technologies [8-10]. In this study, the treatment efficiencies of different AOPs such as $\mathrm{UV} / \mathrm{H}_{2} \mathrm{O}_{2}$ and $\mathrm{UV} / \mathrm{TiO}_{2}$ photocatalysis as well as the ability of microorganisms in aerobic processes for the degradation of MTBE were examined. It has been shown that the integration of photochemical and biological processes is more economical approach for certain organic pollutants in the treatment of water and wastewater [11-13], as a result, the effects of the photochemical pretreatment of $\mathrm{MTBE}$ using $\mathrm{UV} / \mathrm{TiO}_{2}$ photocatalysis on its biological treatment in a sequential batch reactor (SBR) were examined.

\section{EXPERIMENTAL SET-UP AND PROCEDURES}

\subsection{Materials}

HPLC grade MTBE (Aldrich) was used in all experiments. In BOD tests, Polyseed bacteria (United States EPA accepted BOD inoculum) were used. Activated sludge was collected from North Toronto Sewage Treatment Plant, Don Valley, Toronto, Ontario, Canada. Nutrients were prepared for the biological process according to the Standard Methods [14]. Dissolved oxygen (DO) was measured by a DO meter (Model YSI 58).

\subsection{Photochemical reactor}

Photochemical experiments were carried out in a $3 \mathrm{~L}$ batch photoreactor made of glass. The glass photoreactor was immersed in a PVC cylindrical container containing $7 \mathrm{~L}$ of tap water. The water in the container was fed by tap water continuously to keep the temperature of the solution constant within $15-20^{\circ} \mathrm{C}$. This container was also used as a shield to avoid the transmission of light outside the photoreactor. Two different UV lamps (Philips) with wavelength $365 \mathrm{~nm}$ (PL-S 9W/10) or $254 \mathrm{~nm}$ (PL-S 9W TUV) were used, depending on the experiment. In each experiment, a lamp was immersed in the center of the photoreactor. An appropriate amount of hydrogen peroxide and/or $\mathrm{TiO}_{2}$ was added to the aqueous solution. A magnetic stirrer bar was used to mix the solution and to avoid any mass transfer limitations. Samples were withdrawn frequently for immediate analysis. The $\mathrm{pH}$ of the system was reduced from the initial value of 6 to the final value of 4 . This reduction in $\mathrm{pH}$ was mainly due to the generation of organic acids during the photocatalytic reactions.

\subsection{Experimental procedure for the determination of biological oxygen demand}

Biological oxygen demand (BOD) tests were performed according to the Standard Methods [14]. To provide a population of microorganisms to oxidize the organic matters, Poly- seed bacteria were used as the seed source. It was a blend of wide range of bacteria (mixed culture) prepared to be used in the BOD tests. One capsule of Polyseed, containing $100 \mathrm{mg}$ of special microbial cultures, capable of degradation of industrial and municipal wastes, was added to $500 \mathrm{~mL}$ of distilled water and was aerated for 30 minutes before BOD experiments. Since $\mathrm{BOD}_{5}$ tests were conducted for various concentrations of MTBE, different volumes of MTBE solutions were used in each test. Necessary volume of samples was added to $300 \mathrm{~mL}$ BOD bottles individually. $5 \mathrm{~mL}$ of aerated seed material were added to each bottle and the bottle was filled with aerated dilution water containing nutrients that had been already prepared. As a rough check of experimental conditions, a dilution water blank including only seed material and dilution water in BOD bottle was used with each batch of samples. Bottles of samples were incubated (New Brunswick Scientific $\mathrm{C} 25 \mathrm{KC}$ incubator) at $20^{\circ} \mathrm{C}$ without any shaking. After 5 days, the final DO of samples and blank were measured and $\mathrm{BOD}_{5}$ was calculated. The procedure for ultimate $\mathrm{BOD}\left(\mathrm{BOD}_{U}\right)$ tests was conducted for MTBE solution with concentrations of $5,10,30$, and $50 \mathrm{mg} / \mathrm{L}$. The procedure for $\mathrm{BOD}_{U}$ tests was the same as $\mathrm{BOD}_{5}$ except that it had some specific requirements and differences in applications as follows: BOD bottles containing MTBE concentrations of 5, 10, 30 , and $50 \mathrm{mg} / \mathrm{L}$ along with Polyseed solution and dilution water, as described above, were prepared and placed in an incubator at $20^{\circ} \mathrm{C}$. DO was monitored frequently to ensure that low dissolved oxygen or anaerobic condition did not dominate. Whenever DO concentration was less than $2 \mathrm{mg} / \mathrm{L}$, the sample was re-aerated by bubbling air and the concentration of DO after aeration became the initial DO for the next reading.

\subsection{Shake-flask tests for the biodegradation of MTBE by activated sludge mixed culture}

The biodegradation of MTBE by activated sludge mixed culture was carried out in a $1500 \mathrm{~mL}$ shake flask. Mixed cultures (activated sludge) contained $480 \mathrm{mg} / \mathrm{L}$ mixed liquor volatile suspended solid (MLVSS) in the shake-flask cultures. The mixed culture was added into the shake-flask containing $30 \mathrm{mg} / \mathrm{L}$ solution of MTBE. $0.5 \mathrm{~mL}$ of each phosphate buffer, magnesium sulphate, calcium chloride, and ferric chloride solutions were used as nutrients in the amounts to be consistent with the ratio of BOD : $\mathrm{N}: \mathrm{P}$ equal to $100: 5: 1$ [15]. To avoid the lack of nutrients, the same amount $(0.5 \mathrm{~mL}$ of each solution) was added weekly. The flasks were sealed with cotton ball and incubated in a shaker-incubator (C25KC, New Brunswick Scientific) at $20^{\circ} \mathrm{C}$ and shaking speed of $150 \mathrm{rpm}$. Frequently, samples of the culture were filtered (with the pore size of $0.7 \mu \mathrm{m}$ ) for substrate determination and further analysis.

\subsection{Biodegradation of MTBE by acclimated activated sludge using SBR}

To acclimate the activated sludge, a $7 \mathrm{~L}$ SBR, operated at room temperature $\left(25 \pm 1^{\circ} \mathrm{C}\right)$, was used. The bioreactor was 


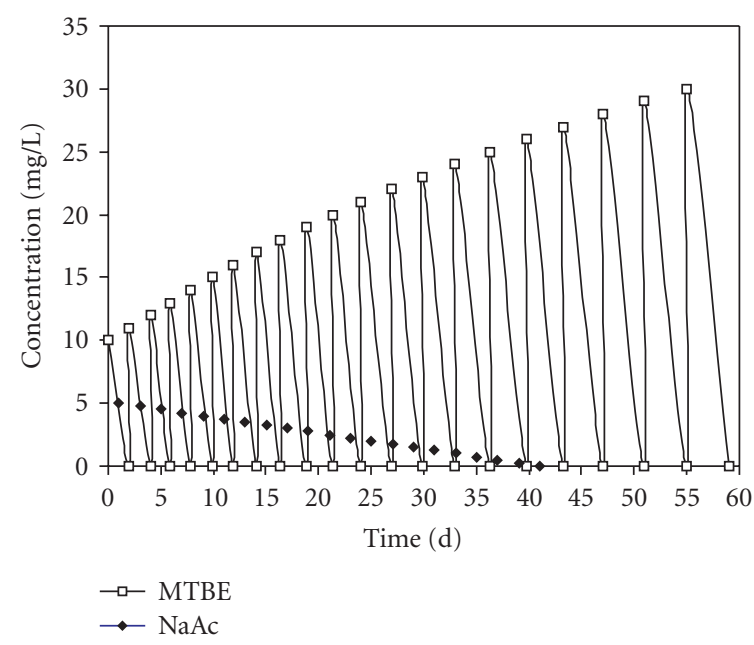

FIgURE 1: Feeding strategy of MTBE and sodium acetate (NaAc) during the acclimatization period of activated sludge in the SBR.

mixed and aerated. Over a period of time, increasing the concentration of the compound of interest was introduced as feed to the activated sludge so that microorganisms gradually utilize the compound as a carbon source. To achieve the endpoint concentration of $30 \mathrm{mg} / \mathrm{L}$ MTBE for acclimation procedure, the bioreactor was primarily filled with $7 \mathrm{~L}$ synthetic wastewater containing $10 \mathrm{mg} / \mathrm{L}$ MTBE and $5 \mathrm{mg} / \mathrm{L}$ sodium acetate as carbon sources, which had $\mathrm{BOD}_{5}$ of $4 \mathrm{mg} / \mathrm{L}$. To ensure that there are adequate nutrients present for microorganisms, the ratio of $\mathrm{BOD}: \mathrm{N}: \mathrm{P}$ equal to $100: 5: 1$ was provided in the solution by addition of $3 \mathrm{~mL}$ phosphate buffer with supplementary nutrients including $1.5 \mathrm{~mL}$ of each magnesium sulphate, calcium chloride, and ferric chloride solution. The same amounts of these nutrients were added whenever the wastewater was refreshed until the end of the acclimatization period. Microbial growth was tracked by the measurement of MLVSS. The values of measured DO during the process were $7.15-8 \mathrm{mg} / \mathrm{L}$. To acclimatize the microorganisms to MTBE, a feeding strategy, as shown in Figure 1, was applied by which the introduction of increasing concentrations of this substrate to the reactor was defined during acclimation period. On the first day, $10 \mathrm{mg} / \mathrm{L}$ of MTBE and $5 \mathrm{mg} / \mathrm{L}$ of sodium acetate were introduced to the SBR. Once MTBE was consumed completely, the next feeding was introduced, where the concentration of MTBE was increased by $1 \mathrm{mg} / \mathrm{L}$ and of sodium acetate (NaAc) was decreased by $0.25 \mathrm{mg} / \mathrm{L}$ per successive additions as shown in Figure 1. This process was continued until the concentrations of $\mathrm{NaAc}$ and MTBE in the feed reached $30 \mathrm{mg} / \mathrm{L}$ and $0 \mathrm{mg} / \mathrm{L}$, respectively.

After the acclimation phase, the feasibility of the remained biomass for the biodegradation of MTBE was investigated in the $7 \mathrm{~L}$ SBR. Following a 10-hour settlement, the remaining solution in the bioreactor was removed. To compensate the discharge of nutrients with discharge of supernatant, phosphate buffer, magnesium sulphate, calcium chloride, and ferric chloride solutions were added to fresh MTBE solution to supply the suggested ratio of BOD : N : P. A fill-and-draw cycle was considered at room temperature.
A complete cycle began with a 6-hour aerated fill period, in which fresh MTBE solution with concentration of $30 \mathrm{mg} / \mathrm{L}$ and nutrients was introduced to the bioreactor and followed by a 65 -hour react period including aeration and mixing. The amount of MTBE was determined in specific time intervals of 10-15 hours. This period ended until the desired concentration of MTBE was achieved. To avoid biomass losses, 7hours were dedicated to the settle period without any aeration or mixing. A clear supernatant was obtained after this period as treated effluent. The process was continued by 3.5hours draw period with no aeration and mixing. The cycle ended by the idle phase of 3.5 hour without any mixing and aeration.

For the combined photocatalytic and biological processes for the MTBE degradation, first, an initial concentration of $50 \mathrm{mg} / \mathrm{L} \mathrm{MTBE}$ and $1.5 \mathrm{~g} / \mathrm{L} \mathrm{TiO}_{2}$ (optimum loading) was introduced to the photoreactor. Experiments were conducted in the photoreactor for a period of 1.5 hours. In a similar way to that for the single biological process, the supernatant of centrifuged pre-treated solution was fed into the SBR.

\subsection{Sample analysis}

MTBE concentrations were analyzed by gas chromatography (GC). After centrifuging the samples for 30 minutes, MTBE was transferred from $10 \mathrm{~mL}$ aqueous samples to the vapour phase by bubbling an inert gas, $\mathrm{He}$, for 11 minutes through the aqueous samples contained in purging chamber of a Tekmar 2016 purge and trap autosampler at ambient temperature. After completion of purging, the trap was heated and the compound was desorbed and transferred into a DB-WAX column $(30 \mathrm{~m} \times 0.25 \mathrm{~mm} \times 0.5 \mu \mathrm{m})$ in a Perkin Elmer Autosystem XL, equipped with flame ionization detector. COD was measured according to the Standard Method [14]. In addition, $\mathrm{H}_{2} \mathrm{O}_{2}$ in the range of $2-500 \mu \mathrm{M}$ was determined by 2,9-dimethyl-1,10-phenantroline (DMP) method [16].

\section{RESULTS AND DISCUSSION}

\subsection{Dark reactions}

A series of control experiments were conducted to quantify the possible loss of MTBE through volatilization or oxidation by dissolved oxygen. In these experiments, solutions of MTBE were stirred in the reactor without UV lamp, $\mathrm{H}_{2} \mathrm{O}_{2}$, or $\mathrm{TiO}_{2}$ for 5 hours. These experiments indicated only $5 \%$ decrease of MTBE during 5 hours. Also, application of each $\mathrm{UV}, \mathrm{H}_{2} \mathrm{O}_{2}$, and $\mathrm{TiO}_{2}$ alone did not show any considerable decrease of MTBE after 5 hours.

\subsection{Photochemical degradation of $M T B E$ by $U V / H_{2} \mathrm{O}_{2}$}

The use of a strong oxidant such as $\mathrm{H}_{2} \mathrm{O}_{2}$ improved the single UV-254 radiation efficiency and considerably increased the destruction of MTBE. It is well known that $\mathrm{H}_{2} \mathrm{O}_{2}$ absorbs light at low wavelengths $(254 \mathrm{~nm})$. However, at low concentrations of $\mathrm{H}_{2} \mathrm{O}_{2}$, sufficient hydroxyl radicals $(\cdot \mathrm{OH})$ are not produced. At higher concentrations, hydroxyl radicals are scavenged by hydrogen peroxide; therefore, the rate of reaction is decreased. Hydroxyl radicals enhanced significantly 


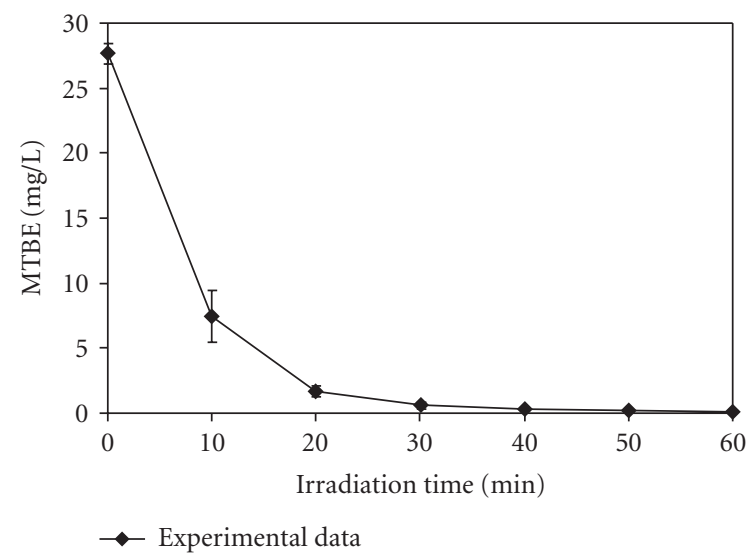

Figure 2: Removal of MTBE by UV-254/ $\mathrm{H}_{2} \mathrm{O}_{2}$ in the first 60 minutes of reaction. $C_{o, \mathrm{MTBE}}=30 \mathrm{mg} / \mathrm{L}, C_{o, \mathrm{H}_{2} \mathrm{O}_{2}}=155 \mathrm{mg} / \mathrm{L}$, molar ratio of $\mathrm{H}_{2} \mathrm{O}_{2} / \mathrm{MTBE}=14$.

the reduction of MTBE in the presence of UV-254 within the range of $90-98 \%$. The molar ratio of $\mathrm{H}_{2} \mathrm{O}_{2}$ /MTBE was in the range of 4-104 with an optimum ratio of 14 . In all cases, more than $90 \%$ conversion was achieved during the first hour of irradiation followed by a very slow rate of degradation.

After determination of optimum molar ratio of $\mathrm{H}_{2} \mathrm{O}_{2} /$ MTBE, a series of experiments were conducted by the optimum value to observe the removal of MTBE in detail in 1 hour. It was observed that more than 90\% MTBE was removed in the first 20 minutes of the reaction as shown in Figure 2. The overall degradation rate constant was estimated by a first-order model with the apparent rate constant of $1.31 \times 10^{-1} \mathrm{~min}^{-1}$.

Stefan et al. [17] performed their experiments at molar ratio of $\mathrm{H}_{2} \mathrm{O}_{2}$ /MTBE equal to approximately 20 and suggested a first-order reaction for decay of MTBE in 20 minutes by $\mathrm{UV} / \mathrm{H}_{2} \mathrm{O}_{2}$ with rate constant of $3.47 \times 10^{-1} \mathrm{~min}^{-1}$. The overall degradation rate in the present study was obtained during 30 minutes. In the present study, the disappearance of hydrogen peroxide within 5 hours followed a zero-order model with the rate constant of $2.13 \times 10^{-1} \mathrm{mg} \mathrm{L}^{-1} \mathrm{~min}^{-1}$ as depicted in Figure 3. Similarly, in Stefan's study, a zero-order rate constant of $3.09 \times 10^{-1} \mathrm{mg} \mathrm{L}^{-1} \mathrm{~min}^{-1}$ for the consumption of $\mathrm{H}_{2} \mathrm{O}_{2}$ in a period of 80 minutes was obtained.

To compare the efficiencies of different UV lights in the degradation of MTBE by $\mathrm{H}_{2} \mathrm{O}_{2}$, two series of experiments were conducted in which UV lamps with 254 and $365 \mathrm{~nm}$ wavelengths were inserted in the photoreactor separately. As illustrated in Figure 4, the degradation of MTBE by $\mathrm{UV}_{254} / \mathrm{H}_{2} \mathrm{O}_{2}$ was faster than that of the $\mathrm{UV}_{365} / \mathrm{H}_{2} \mathrm{O}_{2}$. Higher level of energy in UV-C lamps with 200-280 nm makes it efficient for higher degradation rate of MTBE.

\subsection{Photocatalytic degradation of MTBE by UV/TIO}

UV radiation in the presence of Degussa $\mathrm{P} 25 \mathrm{TiO}_{2}$ highly contributed to the removal of MTBE. The optimal loading of $\mathrm{TiO}_{2}$ was found to be $1.5 \mathrm{~g} / \mathrm{L}$. Photocatalytic degradation of MTBE followed a first-order model with the ap-

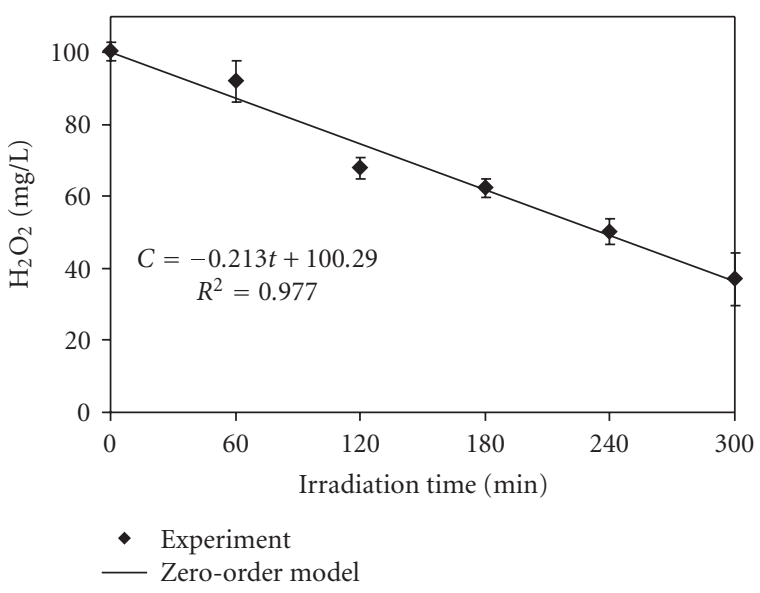

FIgure 3: Disappearance of $\mathrm{H}_{2} \mathrm{O}_{2}$ in the degradation of MTBE by UV-254/ $\mathrm{H}_{2} \mathrm{O}_{2}$ process. $C_{o, \mathrm{MTBE}}=30 \mathrm{mg} / \mathrm{L}, \mathrm{C}_{o}, \mathrm{H}_{2} \mathrm{O}_{2}=155 \mathrm{mg} / \mathrm{L}$, molar ratio of $\mathrm{H}_{2} \mathrm{O}_{2} / \mathrm{MTBE}=14$.

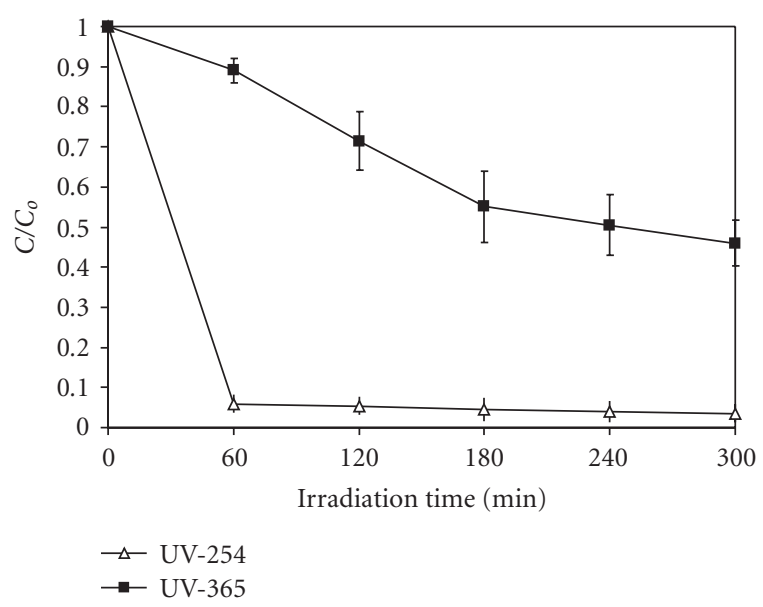

Figure 4: Removal of MTBE by $\mathrm{H}_{2} \mathrm{O}_{2} / \mathrm{UV}-254$ and $\mathrm{H}_{2} \mathrm{O}_{2} / \mathrm{UV}-365$. $C_{o, \mathrm{MTBE}}=10 \mathrm{mg} / \mathrm{L}$, molar ratio of $\mathrm{H}_{2} \mathrm{O}_{2} / \mathrm{MTBE}=14$.

parent rate constant of $1.21 \times 10^{-2} \mathrm{~min}^{-1}$. The comparison between degradation rates of $\mathrm{UV}_{254}$ and $\mathrm{UV}_{365}$ revealed that the light with $254 \mathrm{~nm}$ wavelength had more effectiveness on the degradation of MTBE than that of $365 \mathrm{~nm}$. Figure 5 shows more than $90 \%$ decrease for the degradation of MTBE by $\mathrm{UV}_{254} / \mathrm{TiO}_{2}$ system while the removal of MTBE by $\mathrm{UV}_{365} / \mathrm{TiO}_{2}$ was less than $70 \%$. Although considerable removal of MTBE was observed with both UV-254 and UV365 , the higher level of energy in former could contribute to its degradation and improvement of its rate.

\subsection{Biological degradation of MTBE}

\subsection{1. $B O D_{U}$ determination}

Ultimate BOD may be estimated by using the following firstorder model:

$$
\mathrm{BOD}_{t}=\mathrm{BOD}_{U}\left(1-e^{-k t}\right) .
$$




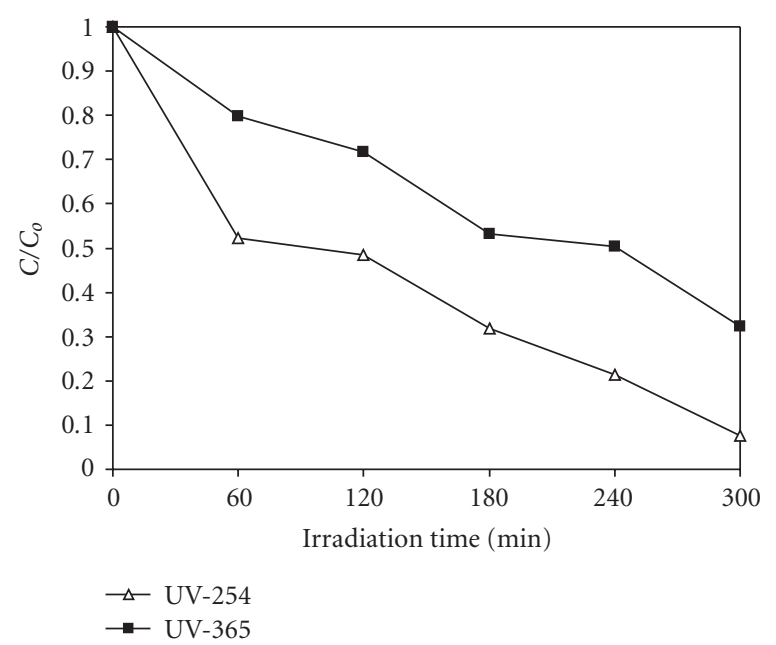

Figure 5: Removal of MTBE by $\mathrm{TiO}_{2} / \mathrm{UV}-254$ and $\mathrm{TiO}_{2} / \mathrm{UV}-365$. $C_{o, \mathrm{MTBE}}=8 \mathrm{mg} / \mathrm{L},\left[\mathrm{TiO}_{2}\right.$ Degussa P25] $=1.5 \mathrm{~g} / \mathrm{L}$ in both cases.

In which $\mathrm{BOD}_{t}, k, t$, and $\mathrm{BOD}_{U}$ are the amount of $\mathrm{BOD}$ at time $t$, reaction rate constant, reaction duration, and the ultimate BOD, respectively. Plotting the BOD versus time for those sample solutions indicated that the removal of MTBE followed a first-order model. It was found that $\mathrm{BOD}_{U}$ for solutions containing $5,10,30$, and $50 \mathrm{mg} / \mathrm{L}$ of MTBE without any pretreatment were $3.55,3.76,4$ and, $4.89 \mathrm{mg} / \mathrm{L}$, which resulted in the first-order rate constants of 0.099, 0.096, 0.118, and $0.101 \mathrm{day}^{-1}$ at $20^{\circ} \mathrm{C}$, respectively. Although the values of $\mathrm{BOD}_{5}$, and therefore the values of $\mathrm{BOD}_{U}$, were higher for solution of $50 \mathrm{mg} / \mathrm{L}$ MTBE, the highest rate of oxygen consumption corresponded to the solution with $30 \mathrm{mg} / \mathrm{L}$ MTBE, which meant more tendencies of microorganisms for usage of this concentration.

\subsubsection{Biodegradation of MTBE by activated sludge mixed culture in shake-flask cultures}

The possibility of MTBE biodegradation in the shake-flask mixed cultures was studied. It was found that during a 30-day time course almost 70\% of the initial amount of MTBE was decreased. The biodegradation of MTBE followed a firstorder reaction rate with the low rate constant of $4.36 \times 10^{-2}$ day $^{-1}$. This means that more than 150 days are required to achieve the acceptable MTBE concentration set by EPA by Drinking Water Advisory [3]. Figure 6 shows the COD changes during the biodegradation of MTBE. COD declined at a slower rate than the concentration of MTBE. While 70\% of MTBE was degraded within 30 days, $40 \%$ of COD was removed at the same time. This implies that the intermediates produced during the biodegradation of MTBE were not readily biodegradable. Although the amount of MTBE was decreased, its biodegradation could not proceed with the produced intermediates and resulted in their accumulation. In addition, TBA and TBF, non-biodegradable intermediates of MTBE, rarely take part in biological reactions [5, 18-20].

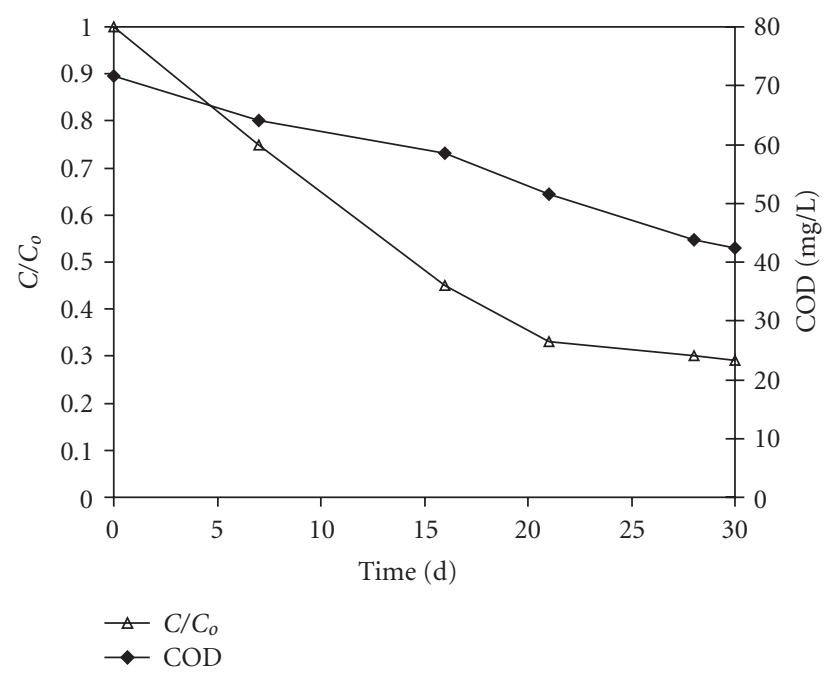

FIGURE 6: COD changes in the biological treatment of MTBE without any pretreatment in the shake-flask culture by nonacclimated activated sludge. $C_{o, \mathrm{MTBE}}=30 \mathrm{mg} / \mathrm{L}, \mathrm{T}=20^{\circ} \mathrm{C} \pm 1^{\circ} \mathrm{C}$.

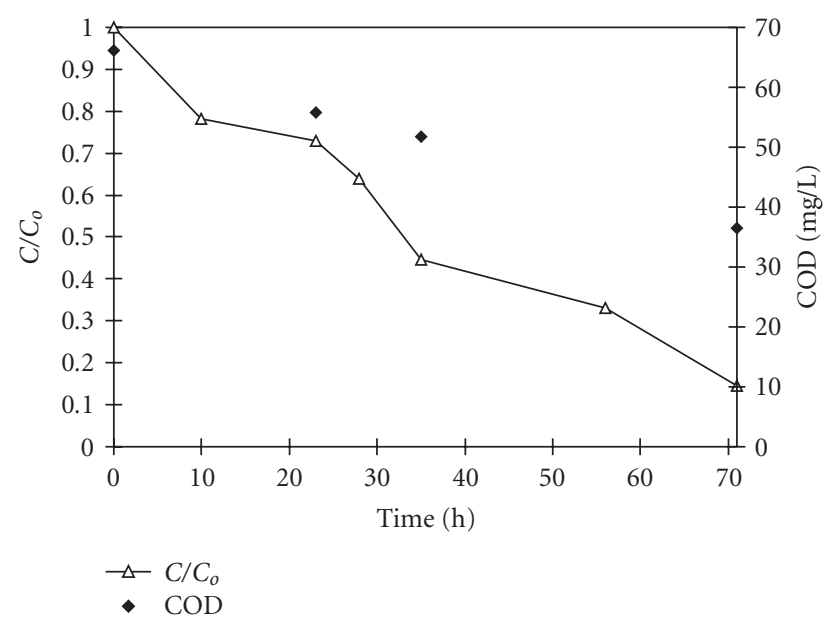

FIGURE 7: COD changes in biological treatment of MTBE without any pretreatment in SBR by acclimated activated sludge. $C_{o, \mathrm{MTBE}}=$ $30 \mathrm{mg} / \mathrm{L}, T=25 \pm 1^{\circ} \mathrm{C}$.

\subsubsection{Biodegradation of MTBE by acclimated activated sludge in a SBR}

An acclimatization process was followed by gradually increasing the concentration of MTBE from 10 to $30 \mathrm{mg} / \mathrm{L}$ as shown in Figure 1. The increase of $100 \mathrm{mg} / \mathrm{L}$ cell dry weight at the end of acclimation period was still confirmed the microorganisms adjustment with new conditions. The endpoint of acclimation process was the presence of $30 \mathrm{mg} / \mathrm{L}$ MTBE in the bioreactor. After accomplishment of acclimation phase, the main biological treatment started. Figure 7 illustrates the trend of biodegradation of MTBE in the SBR. Acclimation led to the increase of biological activity and eventually greater degradation. A zero-order model had the 


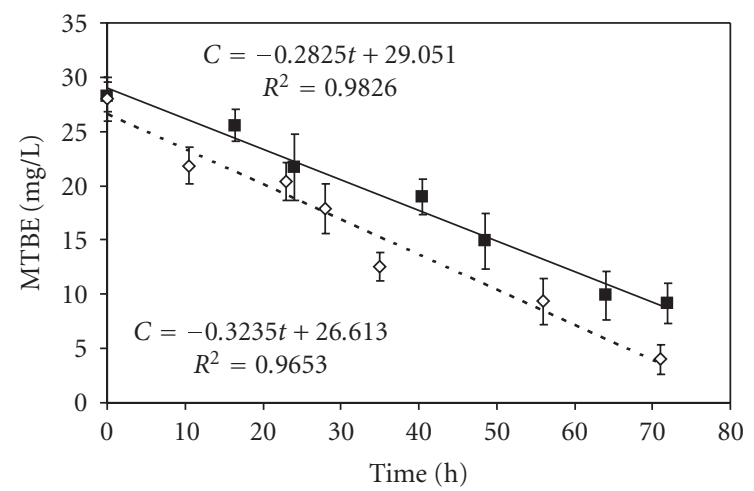

- Experiment, pretreated — Zero-order model, pretreated $\diamond$ Experiment, nontreated $\quad$-... Zero-order model, nontreated

FIgURE 8: Comparison between biological treatment of pretreated MTBE solutions by UV/TiO2 photocatalysis and nontreated MTBE solutions in SBR by acclimated activated sludge. In photoreactor $C_{o, \mathrm{MTBE}}=50 \mathrm{mg} / \mathrm{L}$ and was degraded by $\mathrm{UV} / \mathrm{TiO}_{2}$ for 1.5 hours and then was transferred to the bioreactor. $C_{o, \mathrm{MTBE}}=30 \mathrm{mg} / \mathrm{L}$ for both nontreated and pretreated MTBE in SBR. $T=25 \pm 1^{\circ} \mathrm{C}$.

best fit with obtained results as shown in Figure 8 . The biodegradation rate constant had considerable improvement $\left(3.24 \times 10^{-1} \mathrm{mgL}^{-1} \mathrm{~h}^{-1}\right)$ in comparison to the case of nonacclimated system. This comparison showed that while nonacclimated microorganisms can treat a solution of $30 \mathrm{mg} / \mathrm{L}$ of MTBE in 150 days to reach to the level set by EPA for MTBE in drinking water, the same removal of MTBE can occurr in 90 hours with acclimated microorganisms, which confirms the successful acclimation of microorganisms.

Figure 7 illustrates the results of COD tests for acclimated activated sludge during the removal of MTBE. 85\% degradation of MTBE during 71 hours was accompanied with 45\% removal of COD. This might be due to the fact that acclimated activated sludge, which could degrade MTBE effectively, was not capable of degrading by-products, and therefore these compounds accumulated in the system and slowed down the rate of COD removal. Assembling all these results confirms that the intermediates were not biodegradable and could not be consumed by the acclimated activated sludge either.

\subsubsection{Effects of photocatalytic pretreatment of MTBE on its subsequent biological treatment}

In combined processes, first a solution of $50 \mathrm{mg} / \mathrm{L} \mathrm{MTBE}$ along with the optimum loading of $1.5 \mathrm{~g} / \mathrm{L} \mathrm{TiO}_{2}$ was introduced to the bench-scale slurry photochemical reactor. The reaction was stopped after 1.5 hours so that MTBE concentration was decreased to $30 \mathrm{mg} / \mathrm{L}$. The effluent of the slurry photochemical reactor containing $30 \mathrm{mg} / \mathrm{L}$ of MTBE was centrifuged and the supernatant was transferred to the SBR for further biotreatment by acclimated activated sludge. The biodegradation of MTBE in SBR followed zero-order rate degradation with the rate constant of $2.83 \times 10^{-1} \mathrm{mg} \mathrm{L}^{-1} \mathrm{~h}^{-1}$

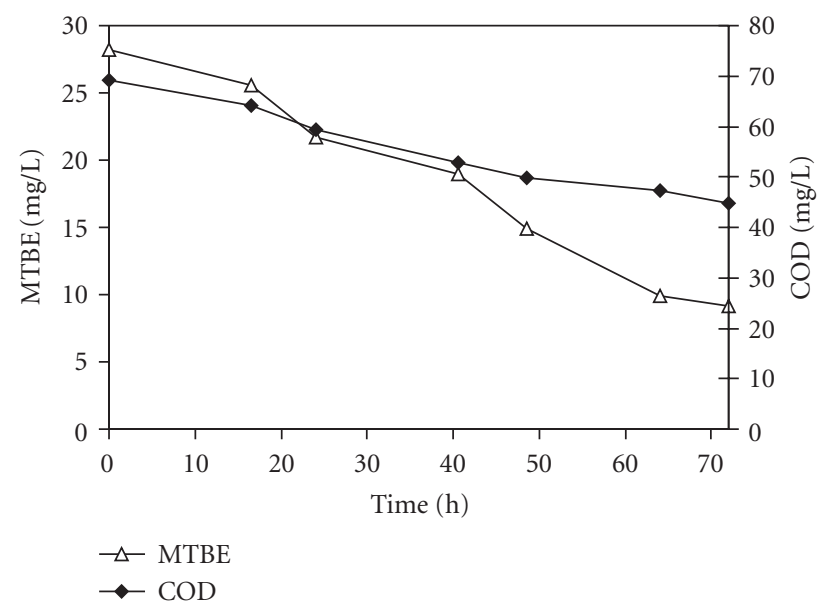

FIGURE 9: COD changes in the biological treatment of pretreated MTBE solution in SBR. In photoreactor $C_{o, \mathrm{MTBE}}=50 \mathrm{mg} / \mathrm{L}$ and was degraded by $\mathrm{UV} / \mathrm{TiO}_{2}$ for 1.5 hours before transferring to the bioreactor so that $C_{o, \mathrm{MTBE}}=30 \mathrm{mg} / \mathrm{L}$ in the bioreactor. $T=25 \pm 1^{\circ} \mathrm{C}$.

as depicted in Figure 8. The removal of COD was also similar to that of nontreated solution as shown in Figure 9, which was slower than the degradation rate of MTBE. 68\% degradation of MTBE occurred with the decrease of COD, but still $65 \%$ COD was not treated and remained in the solution. This implied that the acclimation and the adjustment of microorganisms to MTBE did not necessarily entail their adjustment to by-products since the pretreated MTBE generated nonbiodegradable intermediates. As a result, they were accumulated without any further biodegradation. In addition, similar to the biological treatment alone, more intermediates were produced in the biological reactor so that their presence reflected in the COD values. As Figure 8 depicts, the pretreatment of $\mathrm{MTBE}$ by $\mathrm{UV} / \mathrm{TiO}_{2}$ did not enhance the biodegradability of MTBE. The presence of intermediates coming from the pretreated MTBE interfered with the biotreatment of MTBE and made its biodegradation slower.

\section{CONCLUSIONS}

$\mathrm{UV} / \mathrm{H}_{2} \mathrm{O}_{2}$ and $\mathrm{UV} / \mathrm{TiO}_{2}$ processes removed MTBE effectively from water. Degradation of MTBE with $\mathrm{H}_{2} \mathrm{O}_{2}$ in the presence of UV was a first-order reaction with respect to MTBE and the apparent rate constant was found to be $1.31 \times 10^{-1} \mathrm{~min}^{-1}$. The disappearance of $\mathrm{H}_{2} \mathrm{O}_{2}$ followed a zero-order reaction with rate constant of $2.13 \times 10^{-1} \mathrm{mg} \mathrm{L}^{-1} \mathrm{~min}^{-1}$. Photocatalytic degradation of $\mathrm{MTBE}$ by $\mathrm{UV} / \mathrm{TiO}_{2}$ was achieved with an optimum loading of Degussa $\mathrm{P} 25 \mathrm{TiO}_{2}$ equal to $1.5 \mathrm{~g} / \mathrm{L}$ with apparent first-order rate constant of $1.21 \times 10^{-2} \mathrm{~min}^{-1}$. Combination of $\mathrm{UV} / \mathrm{H}_{2} \mathrm{O}_{2}$ and $\mathrm{UV} / \mathrm{TiO}_{2}$ did not have any advantages over each of them alone. Since MTBE is a poor substrate as sole carbon source, it should be biodegraded under controlled aerobic conditions. Acclimation of microorganisms to MTBE improved its biodegradation and promoted the apparent rate constant from $4.36 \times 10^{-2}$ day $^{-1}$ to 
$3.24 \times 10^{-1} \mathrm{mg} \mathrm{L}^{-1} \mathrm{~h}^{-1}$, but pretreatment of MTBE by photocatalytic process did not improve its biodegradability.

\section{ACKNOWLEDGMENTS}

This research was financially supported by the Natural Science and Engineering Research Council of Canada (NSERC). Partial financial support of Ryerson University for Azadeh Asadi to complete her M.A.Sc. is also appreciated.

\section{REFERENCES}

[1] J. Jacobs, J. Guertin, and C. Herron, MTBE: Effects on Soil and Groundwater Resources, CRC Press LLC, Boca Raton, Fla, USA, 2001.

[2] A. D. Uhler, S. A. Stout, R. M. Uhler, S. D. Emsbo-Mattingly, and K. J. McCarthy, "Accurate chemical analysis of MTBE in environmental media," Environmental Forensics, vol. 2, no. 1, pp. 17-19, 2001.

[3] EPA, last update September 2003 (Accessed June 1st, 2004) http://www.epa.gov/safewater/mtbe.html.

[4] Y.-J. An, D. H. Kampbell, and G. W. Sewell, "Water quality at five marinas in Lake Texoma as related to methyl tert-butyl ether (MTBE)," Environmental Pollution, vol. 118, no. 3, pp. 331-336, 2002.

[5] F. Fayolle, A. François, L. Garnier, et al., "Limitations in MTBE biodegradation [Étapes limitantes dans la biodégradation du MTBE]," Oil and Gas Science and Technology, vol. 58, no. 4, pp. 497-504, 2003.

[6] N. Y. Fortin, M. Morales, Y. Nakagawa, D. D. Focht, and M. A. Deshusses, "Methyl tert-butyl ether (MTBE) degradation by a microbial consortium," Environmental Microbiology, vol. 3, no. 6, pp. 407-416, 2001.

[7] R. D. Barreto, K. A. Gray, and K. Anders, "Photocatalytic degradation of methyl-tert-butyl ether in $\mathrm{TiO}_{2}$ slurries: a proposed reaction scheme," Water Research, vol. 29, no. 5, pp. 1243-1248, 1995.

[8] M. I. Stefan, A. R. Hoy, and J. R. Bolton, "Kinetics and mechanism of the degradation and mineralization of acetone in dilute aqueous solution sensitized by the UV photolysis of hydrogen peroxide," Environmental Science and Technology, vol. 30, no. 7, pp. 2382-2390, 1996.

[9] S. H. Venhuis and M. Mehrvar, "Photolytic treatment of aqueous linear alkylbenzene sulfonate," Journal of Environmental Science and Health, Part A, vol. 40, no. 9, pp. 1731-1739, 2005.

[10] G. B. Tabrizi and M. Mehrvar, "Pilot-plant study for the photochemical treatment of aqueous linear alkylbenzene sulfonate," Separation and Purification Technology, vol. 49, no. 2, pp. 115-121, 2006.

[11] G. B. Tabrizi and M. Mehrvar, "Integration of advanced oxidation technologies and biological processes: recent developments, trends, and advances," Journal of Environmental Science and Health, Part A, vol. 39, no. 11-12, pp. 3029-3081, 2004.

[12] A. Hamad, A. Aidan, M. Fayed, and M. Mehrvar, "Experimental investigation of phenolic wastewater treatment using combined activated carbon and UV processes," Clean Technologies and Environmental Policy, vol. 7, no. 3, pp. 177-181, 2005.

[13] M. Mehrvar and G. B. Tabrizi, "Combined photochemical and biological processes for the treatment of linear alkylbenzene sulfonate in water," Journal of Environmental Science and Health, Part A, vol. 41, no. 4, pp. 581-597, 2006.
[14] A. E. Greenberg, L. S. Clesceri, and A. D. Eaton, Eds., Standard Methods for the Examination of Water and Wastewater, American Public Health Association, American Water Works Association and The Water Environment Federation, Washington, DC, USA, 20th edition, 1998.

[15] W. W. Eckenfelder Jr., Industrial Water Pollution Control, McGraw-Hill, Boston, Mass, USA, 3rd edition, 2000.

[16] K. Kosaka, H. Yamada, S. Matsui, S. Echigo, and K. Shishida, "Comparison among the methods for hydrogen peroxide measurements to evaluate advanced oxidation processes: application of a spectrophotometric method using copper(II) ion and 2,9-dimethyl-1,10-phenanthroline," Environmental Science and Technology, vol. 32, no. 23, pp. 3821-3824, 1998.

[17] M. I. Stefan, J. Mack, and J. R. Bolton, "Degradation pathways during the treatment of methyl tert-butyl ether by the UV/H2O2 process," Environmental Science and Technology, vol. 34, no. 4, pp. 650-658, 2000.

[18] R. J. Steffan, K. McClay, S. Vainberg, C. W. Condee, and D. Zhang, "Biodegradation of the gasoline oxygenates methyl tert-butyl ether, ethyl tert-butyl ether, and tert-amyl methyl ether by propane-oxidizing bacteria," Applied and Environmental Microbiology, vol. 63, no. 11, pp. 4216-4222, 1997.

[19] J. P. Salanitro, L. A. Diaz, M. P. Williams, and H. L. Wisniewski, "Isolation of a bacterial culture that degrades methyl t-butyl ether," Applied and Environmental Microbiology, vol. 60, no. 7, pp. 2593-2596, 1994.

[20] G. Hernandez-Perez, F. Fayolle, and J.-P. Vandecasteele, "Biodegradation of ethyl t-butyl ether (ETBE), methyl t-butyl ether (MTBE) and t-amyl methyl ether (TAME) by Gordonia terrae," Applied Microbiology and Biotechnology, vol. 55, no. 1, pp. 117-121, 2001. 


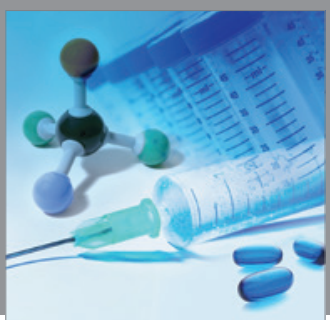

International Journal of

Medicinal Chemistry

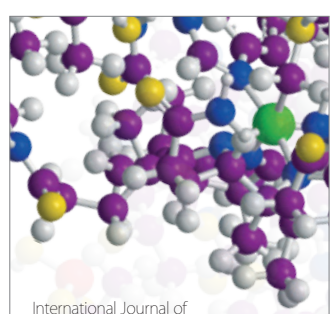

Carbohydrate Chemistry

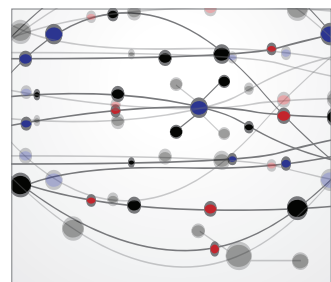

The Scientific World Journal
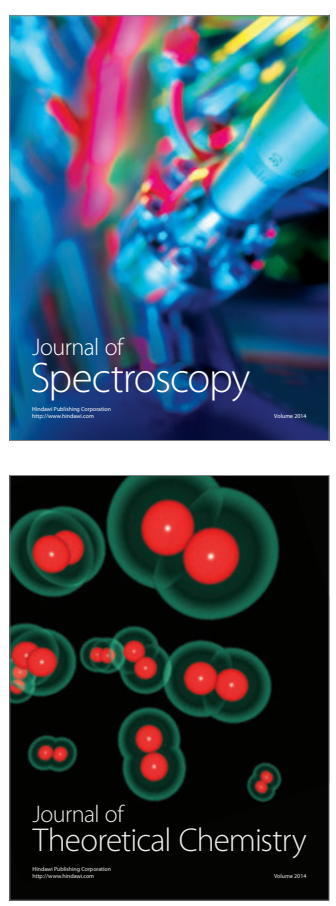
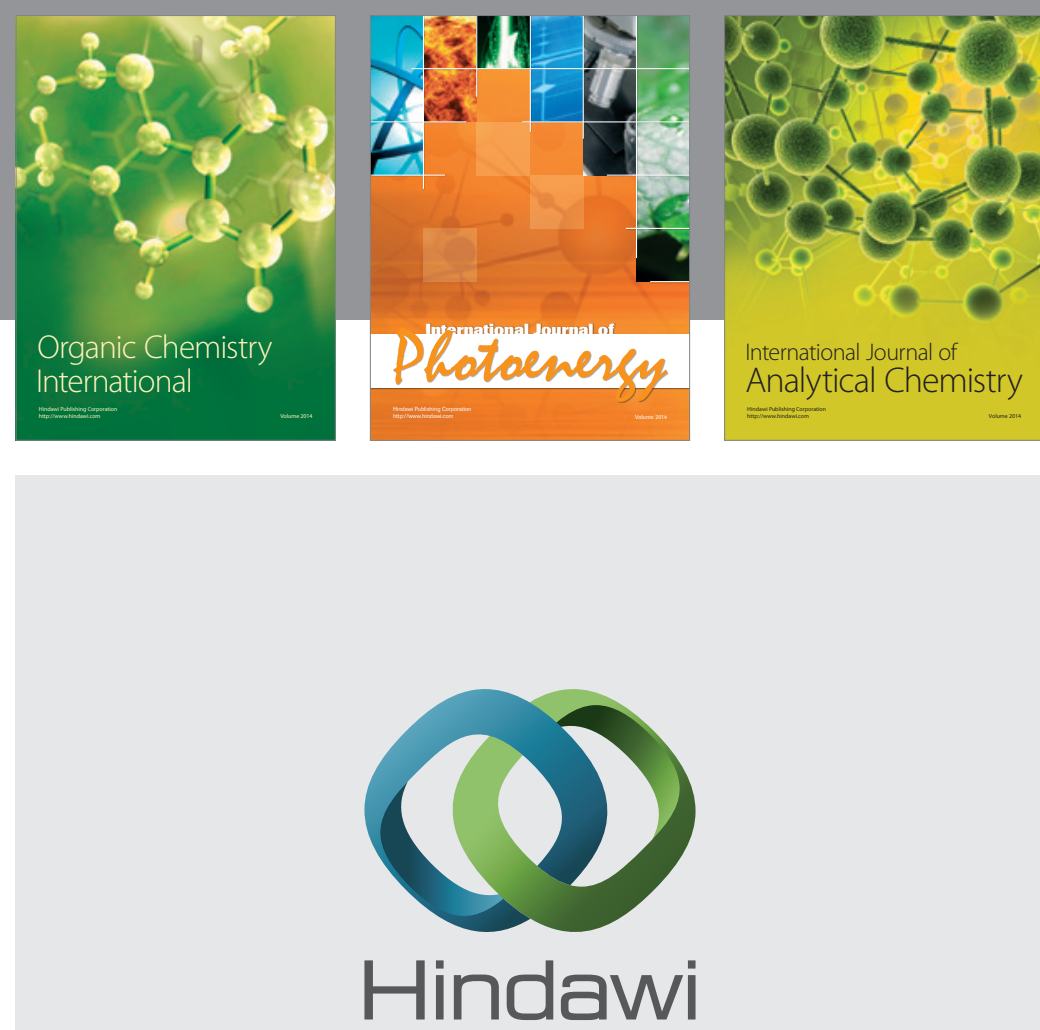

Submit your manuscripts at

http://www.hindawi.com
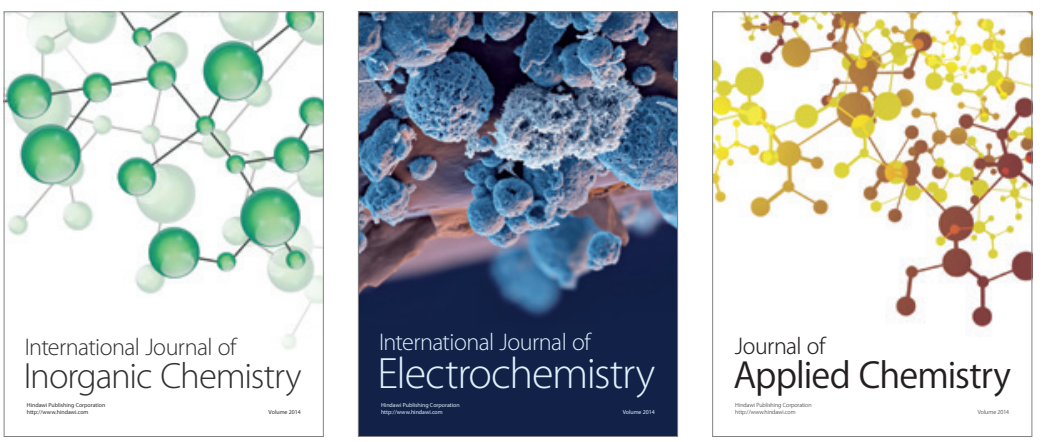

Journal of

Applied Chemistry
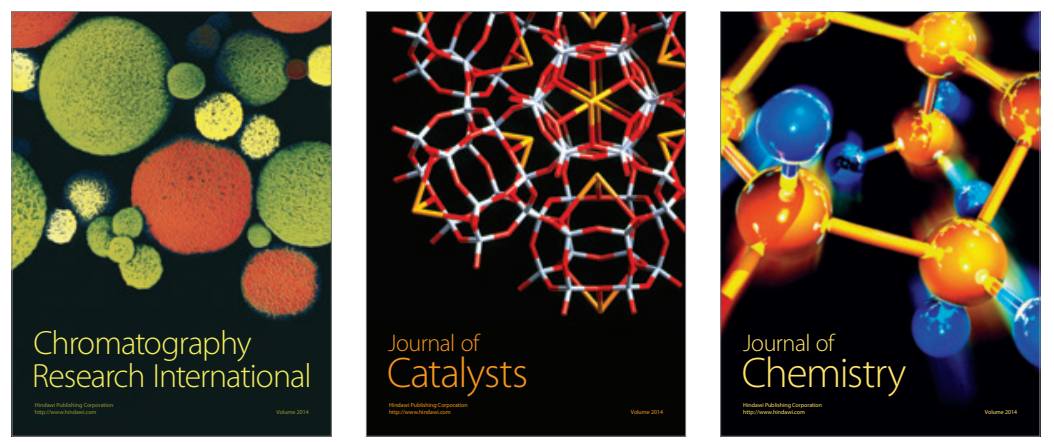
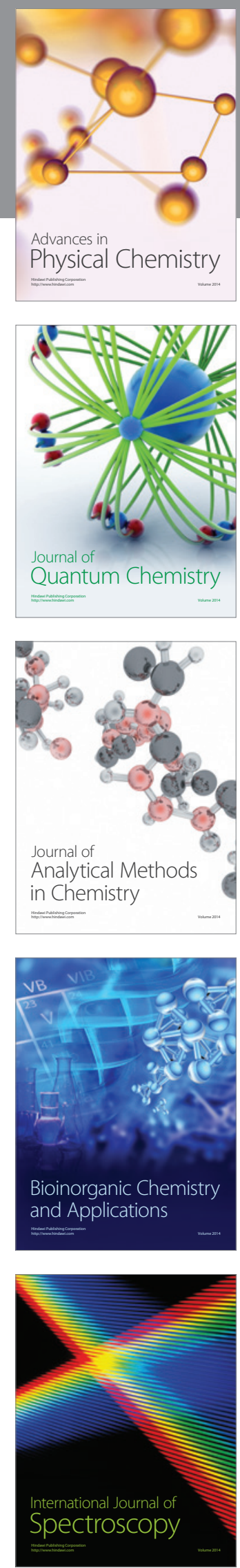